\title{
Can ${ }^{11} \mathrm{C}-\mathrm{PiB}-\mathrm{PET}$ Relative Delivery $\mathrm{R}_{1}$ or ${ }^{11} \mathrm{C}-\mathrm{PiB}-\mathrm{PET}$ Perfusion Replace ${ }^{18} \mathrm{~F}-\mathrm{FDG}-\mathrm{PET}$ in the Assessment of Brain Neurodegeneration?
}

Francisco P.M. Oliveira ${ }^{\mathrm{a}, \mathrm{b}}$, Ana Paula Moreira ${ }^{\mathrm{c}}$, Alexandre de Mendonça $^{\mathrm{d}}$, Ana Verdelho ${ }^{\mathrm{e}}$, Carolina Xavier ${ }^{\mathrm{a}}$, Dalila Barroca ${ }^{\mathrm{a}}$, Joana Rio ${ }^{\mathrm{a}}$, Eva Cardoso $^{\mathrm{a}}$, Ângela Cruz ${ }^{\mathrm{a}}$, Antero Abrunhosa ${ }^{\mathrm{a}}$ and Miguel Castelo-Branco ${ }^{\mathrm{a}, \mathrm{b}}$ ${ }^{a}$ CIBIT, Institute for Nuclear Sciences Applied to Health (ICNAS - P), University of Coimbra, Coimbra, Portugal ${ }^{\mathrm{b}}$ Institute for Biomedical Imaging and Life Sciences (IBILI), Faculty of Medicine, University of Coimbra, Coimbra, Portugal

${ }^{\mathrm{c}}$ Nuclear Medicine Department, Coimbra Hospital and University Centre, Coimbra, Portugal

${ }^{\mathrm{d}}$ Department of Neurology and Laboratory of Neurosciences, Faculty of Medicine, University of Lisbon, Lisbon, Portugal

${ }^{\mathrm{e}}$ Department of Neurosciences and Mental Health, Santa Maria Hospital-CHLN, ISAMB, University of Lisbon, Lisbon, Portugal

Accepted 11 June 2018

\begin{abstract}
.
Background: Pittsburgh Compound B (PiB) positron emission tomography (PET) is used to visualize in vivo amyloid plaques in the brain. Frequently the PiB examinations are complemented with a fluorodeoxyglucose (FDG) PET scan to further assess neurodegeneration.

Objective: Our goal is to identify alternative correlates of FDG images by assessing which kinetic methods originate PiB derived relative delivery ratio $\left(\mathrm{R}_{1}\right)$ images that can be correlated with the FDG images, and to compare them with PiB perfusion ( $\mathrm{pPiB}$ ) images obtained from the early-phase of $\mathrm{PiB}$ acquisition.

Methods: We selected 52 patients with cognitive impairment who underwent a dynamic PiB and FDG acquisitions. To compute the $\mathrm{R}_{1}$ images, two simplified reference tissue models (SRTM and SRTM2) and two multi-linear reference tissue models (MRTM and MRTM2) were used. The pPiB images were obtained in two different time intervals.

Results: All six types of images were of good quality and highly correlated with the FDG images (mean voxelwise withinsubjects $r>0.92$ ). The higher correlation was found for FDG- $\mathrm{R}_{1}(\mathrm{MRTM})$. Regarding the voxelwise regional correlation, the higher mean all brain correlations was $r=0.825$ for FDG- $\mathrm{R}_{1}(\mathrm{MRTM})$ and statistically significant in the whole brain analysis. Conclusion: $A l l \mathrm{R}_{1}$ and $\mathrm{pPiB}$ images here tested have potential to assess the metabolic impact of neurodegeneration almost as reliably as the FDG images. However, this is not enough to validate these images for a single-subject analysis compared with the FDG image, and thus they cannot yet be used clinically to replace the FDG image before such evaluation.
\end{abstract}

Keywords: Alzheimer's disease, ${ }^{11} \mathrm{C}-\mathrm{PIB}$, compartmental models, ${ }^{18} \mathrm{~F}-\mathrm{FDG}$, neurodegeneration, perfusion

\footnotetext{
${ }^{*}$ Correspondence to: Miguel Castelo-Branco, ICNAS Polo 3, 3000-548, Coimbra, Portugal. Tel.: +351 239488514; E-mail: mcbranco@fmed.uc.pt.
}

\section{INTRODUCTION}

Positron emission tomography (PET) imaging with Pittsburgh Compound B (PiB) labeled with ${ }^{11} \mathrm{C}$ 
tracer has been increasingly used in many nuclear medicine centers to visualize in vivo amyloid plaques in the brain, which is a core molecular imaging feature of Alzheimer's disease (AD) [1]. However, the presence of high levels of amyloid plaques in the brain does not directly imply concurrent neural degeneration. Thus, regional cerebral blood flow (rCBF) and regional cerebral glucose metabolism have been extensively used as indirect biomarkers of synaptic dysfunction and neurodegeneration. Previous studies have shown a tight coupling between $\mathrm{rCBF}$ and regional glucose metabolism [2]. This last one has frequently been assessed with fluorodeoxyglucose (FDG) labeled with ${ }^{18} \mathrm{~F}$ for PET systems.

Frequently, patients with cognitive impairments for whom a differential diagnosis is difficult to provide are requested to undergo double PET imaging: $\mathrm{PiB}$ (or other available amyloid tracer, as florbetaben or florbetapir) and FDG, to help solve such diagnostic difficulties. However, this has the potential drawback of cost and radiation exposure increase. Complementary surrogate measures that avoid these problems are therefore worth being investigated. As a possible alternative, if a dynamic PiB PET acquisition is performed, beyond the parametric binding potential $\left(\mathrm{BP}_{\mathrm{ND}}\right)$ image, the relative regional cerebral blood flow $\left(\mathrm{R}_{1}=K_{1} / k_{1}^{\prime}\right)$ parametric image can be estimated for each brain voxel from pharmacokinetic analyses of $\mathrm{PiB}$, thereby providing such type of alternative (Fig. 1).

A previous study has suggested that there is a significant correlation between the FDG images and the $\mathrm{R}_{1}$ images [3]. Two other studies also have found a significant correlation between the FDG and the $\mathrm{PiB}$ perfusion (pPiB) images $[4,5]$. In addition, Chen and colleagues [6] showed that the relative delivery ratio $\mathrm{R}_{1}$ of $\mathrm{PiB}$ is highly correlated with relative $\mathrm{rCBF}$ measured by ${ }^{15} \mathrm{O}$-water normalized to cerebellum. Other research groups have focused on these issues using other available markers of amyloid plaques. For instance, Daerr et al. [7] showed a good correlation of early acquisitions of $\left[{ }^{18} \mathrm{~F}\right]$ florbetaben (FBB) PET with FDG PET [7], and Lin et al. [8] showed that Mini-Mental State Examination (MMSE) scores are significantly associated with the degree of perfusion impairment as assessed by early phase of ${ }^{18} \mathrm{~F}-\mathrm{AV}-45$ PET on a dataset of patients with $\mathrm{AD}$, mild cognitive impairment (MCI), and healthy controls (HC).

Our main goal is to assess which is the best solution to obtain an image from the PiB PET acquisition

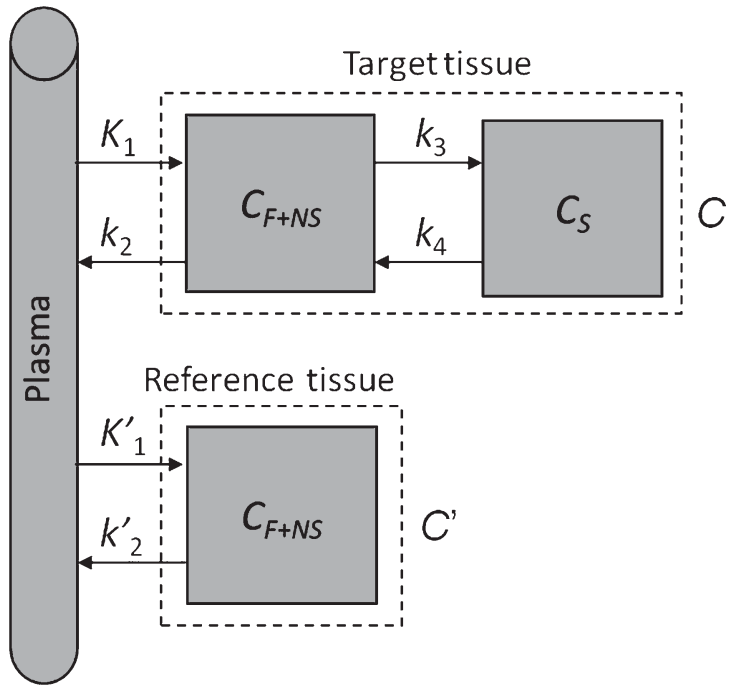

Fig. 1. Two-tissue compartment model with reference region. $C_{F+N S}$ is the concentration due to free and nonspecific binding, $C_{S}$ is the concentration due to specific binding.

comparable with the FDG PET image, and thus to provide a proxy measure of synaptic dysfunction and neurodegeneration. We considered four models to obtain the $\mathrm{R}_{1}$ images and two time periods to obtain the $\mathrm{pPiB}$ images. For the $\mathrm{R}_{1}$ images, we used the simplified reference tissue model (SRTM), the multi-linear reference tissue model (MRTM), the SRTM with fixed $k_{2}^{\prime}$ (SRTM2), and the MRTM with fixed $k_{2}^{\prime}$ (MRTM2). To generate the pPiB images, we considered two time periods that have been considered to be optimal $[4,9,10]$, one between 0 and $6 \mathrm{~min}(\mathrm{pPiB}(0-6))$ and the other between 1 and $8 \mathrm{~min}$ $(\mathrm{pPiB}(1-8))$. A second goal is to validate the results obtained by Meyer and colleagues [3] but now using a different and larger dataset of patients.

\section{MATERIALS AND METHODS}

\section{Patients}

A total of 52 patients who underwent ${ }^{11} \mathrm{C}-\mathrm{PiB}$ PET and ${ }^{18}$ F-FDG PET examinations were included in this study. We included all patients from Institute of Nuclear Science Applied to Health (ICNAS, University of Coimbra), except patients with head movements during the acquisitions above the scanner resolution. All patients gave written informed consent, as approved by the Ethics committee of the University of Coimbra. Demographic and clinical information are summarized in Table 1 . The criteria 
Table 1

Synthesis of clinical and demographic data of the patients

\begin{tabular}{lccc}
\hline Subjects & $\begin{array}{c}\text { Number of } \\
\text { patients (M/F) }\end{array}$ & $\begin{array}{c}\text { Age } \\
(\text { mean } \pm \text { SD) }\end{array}$ & $\begin{array}{c}\text { Amyloid burden } \\
\text { negative / low / high }\end{array}$ \\
\hline $\mathrm{AD}$ & $20(6 / 14)$ & $68 \pm 6$ & $1 / 0 / 19$ \\
$\mathrm{MCI}$ & $19(8 / 11)$ & $69 \pm 7$ & $6 / 7 / 6$ \\
$\mathrm{PPA}$ & $5(3 / 2)$ & $66 \pm 7$ & $2 / 0 / 3$ \\
$\mathrm{FTD}$ & $4(1 / 3)$ & $72 \pm 10$ & $3 / 1 / 0$ \\
Other & $4(1 / 3)$ & $54 \pm 10$ & $4 / 0 / 0$ \\
Total & $52(19 / 33)$ & $67 \pm 8$ & $16 / 8 / 28$ \\
\hline
\end{tabular}

for the diagnosis of the neurodegenerative disorders were: probable AD dementia according to NINCDSADRDA criteria [11], MCI due to AD following the NINCDS-ADRDA criteria [12], primary progressive aphasia according to the recommendations of GornoTempini and colleagues [13], and the behavioral variant of frontotemporal dementia (FTD) according to the criteria of the International Behavioural Variant FTD Criteria Consortium [14].

We also categorized PiB-PET images in three groups-amyloid negative, amyloid borderline/low burden, and high amyloid deposition-following our local classifier based on support vector machines (SVM), which uses the voxelwise brain grey matter standardized uptake value ratio (SUVR) computed from the PiB-PET images, and using the cerebellar grey matter as reference region.

\section{PET acquisitions}

All ${ }^{11} \mathrm{C}$-PIB PET and ${ }^{18}$ F-FDG PET acquisitions were performed in the same scanner (Philips PET/CT Gemini GXL), preceded by a low-dose brain CT acquisition for attenuation correction. Except for one patient, both scans were acquired on the same day $\left({ }^{18} \mathrm{~F}-\mathrm{FDG}\right.$ was injected approximately $2 \mathrm{~h}$ after ${ }^{11} \mathrm{C}$ $\mathrm{PiB}$ injection). For each acquisition, the patient's head was restrained with a soft elastic tape. All patients fasted for at least $6 \mathrm{~h}$ before ${ }^{18} \mathrm{~F}$-FDG injection.

The ${ }^{11} \mathrm{C}-\mathrm{PiB}$ PET acquisitions were dynamic, lasted for $90 \mathrm{~min}$ (37 frames: $4 \times 15 \mathrm{~s}+8 \times 30 \mathrm{~s}+$ $9 \times 60 s+2 \times 180 s+14 \times 300 s)$ and started immediately after the intravenous bolus injection of approximately $555 \mathrm{MBq}$ of ${ }^{11} \mathrm{C}-\mathrm{PiB}$. The ${ }^{18} \mathrm{~F}-\mathrm{FDG}$ PET acquisitions were static, started approximately $30 \mathrm{~min}$ after the intravenous bolus injection of approximately $185 \mathrm{MBq}$ of ${ }^{18} \mathrm{~F}-\mathrm{FDG}$ and lasted for $30 \mathrm{~min}$.

Both acquisitions were reconstructed using the LOR RAMLA algorithm (Philips PET/CT Gemini GXL) with attenuation and scatter correction. In both cases, an isotropic voxel size of $2 \mathrm{~mm}$ was defined.

\section{Quantification of pPiB images and relative} delivery ratio $R_{1}$ parametric images

Voxelwise $\mathrm{pPiB}(0-6 \mathrm{~min})$ and $\mathrm{pPiB}(1-8 \mathrm{~min})$ images were computed by cumulatively adding the frames in the time periods between 0 and $6 \mathrm{~min}$ and between 1 and $8 \mathrm{~min}$ after injection, respectively. These time intervals where chosen since they were found optimal in previous works.

Four different approaches were used for quantification of relative delivery ratio $\mathrm{R}_{1}$ : MRTM, SRTM, MRTM2 and SRTM2. For all four methods, the cerebellar grey matter was used as reference region. This choice is based on the work of Thal et al. [15] where the authors showed that there is no amyloid deposition in the cerebellar grey matter before the phase 5 (advanced cases) and even in this phase the deposition is very small. This was confirmed using PiB PET by Klunk et al. [16].

\section{SRTM and SRTM2}

We implemented the SRTM [17] method using basis functions [18], since this solution is more stable than non-linear least squares method at the voxel level. The simplified operational equation is

$$
C(t)=\theta_{1} C^{\prime}(t)+\theta_{2} C(t) \otimes e^{-\theta_{s} t}
$$

where $C$ is the concentration in the target region, $C^{\prime}$ is the concentration in the reference region and $\otimes$ is the convolution operator. We have considered 200 values for $\theta_{3}$ between $0.017 \mathrm{~min}^{-1}$ and $0.137 \mathrm{~min}^{-1}$ and, for each $\theta_{3}$, the other two parameters were estimated using linear least squares.

The SRTM2 is based on SRTM but implemented in two steps [19]. In the first one, the SRTM is applied to compute the $\mathrm{BP}_{\mathrm{ND}}, \mathrm{R}_{1}$ and $k_{2}$ at the voxel level [18]. Then, $k_{2}^{\prime}$ is derived as $k_{2}^{\prime}=\left(B P_{N D}-1\right) k_{2} / \mathrm{R}_{1}$. Since $k_{2}^{\prime}$ should be the same for all brain voxels, it is estimated by computing the median of all $k_{2}^{\prime}$ obtained. Then, in the second step, it is fixed and the equation is rearranged, with only two parameters remaining to be optimized [19]. As for the SRTM, we implemented SRTM2 using basis functions and the same range of values for $\theta_{3}$. Since $k_{2}^{\prime}$ estimation is very sensitive to noise when computed at the voxel level, to compute it in the first step we have resampled the original dynamic images with voxels of $8 \times 8 \times 8 \mathrm{~mm}^{3}$ and only considered the values of $k_{2}^{\prime}$ when $0<\mathrm{BP}_{\mathrm{ND}}<3$, $k_{2}>0$ and $\mathrm{R}_{1}>0$. 


\section{MRTM and MRTM2}

The MRTM implemented is based on the following multi-linear reference tissue model equation [20]:

$$
C(T)=-\frac{V}{V^{\prime} b} \int_{0}^{T} C^{\prime}(t) d t+\frac{1}{b} \int_{0}^{T} C(t) d t-\frac{V}{V^{\prime} k_{2}^{\prime} b} C^{\prime}(T)
$$

which has three parameters to be optimized: $\gamma_{1}=$ $-\frac{V}{V^{\prime} b}, \gamma_{2}=\frac{1}{b}, \gamma_{3}=-\frac{V}{\left(V^{\prime} k_{2}^{\prime} b\right)}$. It can be done efficiently using linear least squares. Then, $B P_{N D}=$ $-\left(\frac{\gamma_{1}}{\gamma_{2}}+1\right), k_{2}=-\gamma_{2}$ and $\mathrm{R}_{1}=\gamma_{3}$. In the experimental analysis we did, very noisy $\mathrm{BP}_{\mathrm{ND}}$ images were obtained simultaneously with negative values of $k_{2}$. Thus, we constrained the $k_{2}$ as a minimum of $0.012 \mathrm{~min}^{-1}$. This value was established experimentally based on the observation of the values of $k_{2}$ obtained in a subset of the images considering 10 regions of interest (anterior cingulate, caudate, mesial temporal cortex, prefrontal cortex, posterior cingulate, putamen, precuneus, occipital cortex, parietal superior, and inferior cortex).

MRTM2 is a two-step implementation of the MRTM [20]. In the first step, the median of $k_{2}^{\prime}$ is estimated using MRTM and then fixed in the second step. By fixing $k_{2}^{\prime}$, the equation can be rearranged to the following

$$
C(T)=-\frac{V}{V^{\prime} b}\left(\int_{0}^{T} C^{\prime}(t) d t+\frac{1}{k_{2}^{\prime}} C^{\prime}(T)\right)+\frac{1}{b} \int_{0}^{T} C(t) d t
$$

and thus obtaining $B P_{N D}=-\left(\frac{\gamma_{1}}{\gamma_{2}}+1\right), \mathrm{R}_{1}=\frac{\gamma_{1}}{k_{2}^{\prime}}$ and $k_{2}=-\gamma_{2}$.

\section{Implementation of algorithms}

For the computation of the $\mathrm{R}_{1}$ and $\mathrm{pPiB}$ images, in the initial step a sum image was built using all frames and then the sum image was registered to the Montreal Neurological Institute (MNI) space using in-house made software using a deformable model based on cubic B-splines and a PiB sum image template as reference image. Next, all frames of the dynamic image were also registered using the same geometric transformation. Image registration algorithms were implemented using the Insight Toolkit (ITK) software library, version 3.20, and based on the optimization of the mutual information similarity measure [21]. Parameter optimization was done using the Vision Numerics Library (VNL) available in the ITK [21]. The sum PiB template is in the MNI space and was built in our institution using a set of normal PiB scans and with the help of the MRI of the subjects.

\section{${ }^{18}$ F-FDG image processing}

The ${ }^{18}$ F-FDG images were first rigidly registered with the correspondent $\mathrm{R}_{1}(\mathrm{MRTM})$ image and then registered to the MNI space using the transformation found when the respective ${ }^{11} \mathrm{C}$-PiB images were registered to the MNI space.

\section{Statistics}

\section{Intensity normalization}

The $\mathrm{pPiB}, \mathrm{R}_{1}$ and ${ }^{18} \mathrm{~F}-\mathrm{FDG}$ registered images were smoothed with a Gaussian kernel with $8 \mathrm{~mm}$ full width at half maximum and then intensity normalized. The intensity normalization was done independently per each image by dividing each voxel value by the mean brain values of the respective image. The brain voxels were defined based on the MNI template.

\section{Within-subjects correlation}

For each subject, the mean Pearson correlation coefficients between the pairs FDG-pPiB(0-6 min), FDG-pPiB(1-8 min), FDG-R 1 (MRTM), FDG-R 1 (MRTM2), FDG-R 1 (SRTM), and FDG-R 1 (SRTM2) were computed. For each FDG image, all brain voxels were correlated with the correspondent voxels of the $\mathrm{pPiB}$ or $\mathrm{R}_{1}$ image, yielding a correlation coefficient per pair of images per subject. Comparison of correlations was performed using repeated measures ANOVA.

To assess differences of the correlation among the amyloid burden groups (negative, low and high) the Kruskal-Wallis test was used. ANOVA and KruskalWallis test were performed using the Statistical Package for the Social Sciences (SPSS, v20).

\section{Voxelwise regional correlation}

Since variations of cerebral blood flow and glucose metabolism coupling are not homogeneous across all brain regions [22], we assessed the regional correlation at voxel level. Per each voxel location, we computed the correlation between the group of the FDG images against the groups of $\mathrm{pPiB}$ or $\mathrm{R}_{1}$ images. Thus, we obtained the whole-brain correlation distribution.

Correlation significance was assessed per each voxel using Benjamini-Hochberg false discovery rate (FDR) correction for multiple comparisons 


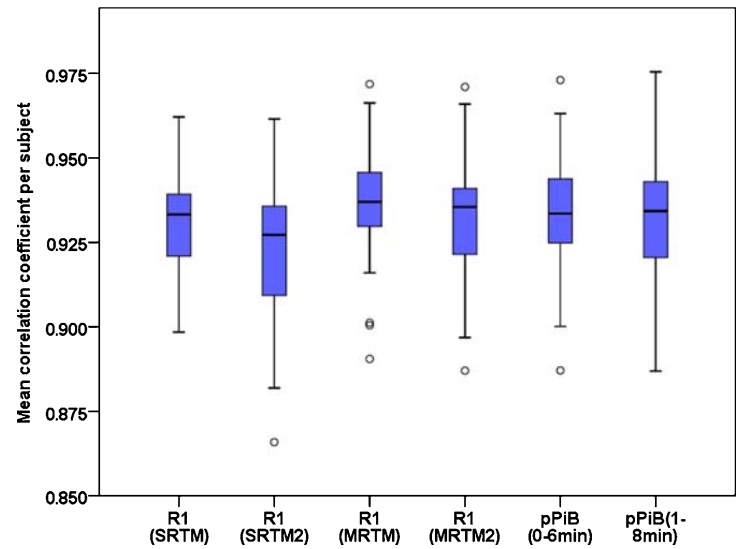

Fig. 2. Boxplot graph comparing the within subjects correlation coefficient between the FDG images and the $\mathrm{R}_{1}$ (SRTM), $\mathrm{R}_{1}$ (SRTM2), $\mathrm{R}_{1}$ (MRTM), $\mathrm{R}_{1}$ (MRTM2), $\mathrm{pPiB}(0-6 \mathrm{~min})$ and $\mathrm{pPiB}(1-8 \mathrm{~min})$ images. with $\alpha=0.05$. Differences in the mean whole brain voxelwise correlation were assessed using ANOVA.

\section{RESULTS}

\section{Within-subjects correlation}

Results of the Pearson linear correlation coefficient between FDG, $\mathrm{R}_{1}$ and $\mathrm{pPiB}$ images are shown in Fig. 2. Mean \pm standard deviation values were $0.929 \pm 0.016,0.924 \pm 0.020,0.936 \pm 0.015$, $0.933 \pm 0.016,0.933 \pm 0.016$, and $0.932 \pm 0.018$, for the correlations FDG-R $($ SRTM), FDG-

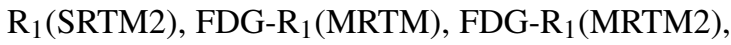
FDG-pPiB(0-6 min), and FDG-pPiB(1-8 min), respectively. This means that the $\mathrm{R}_{1}$ and $\mathrm{pPiB}$
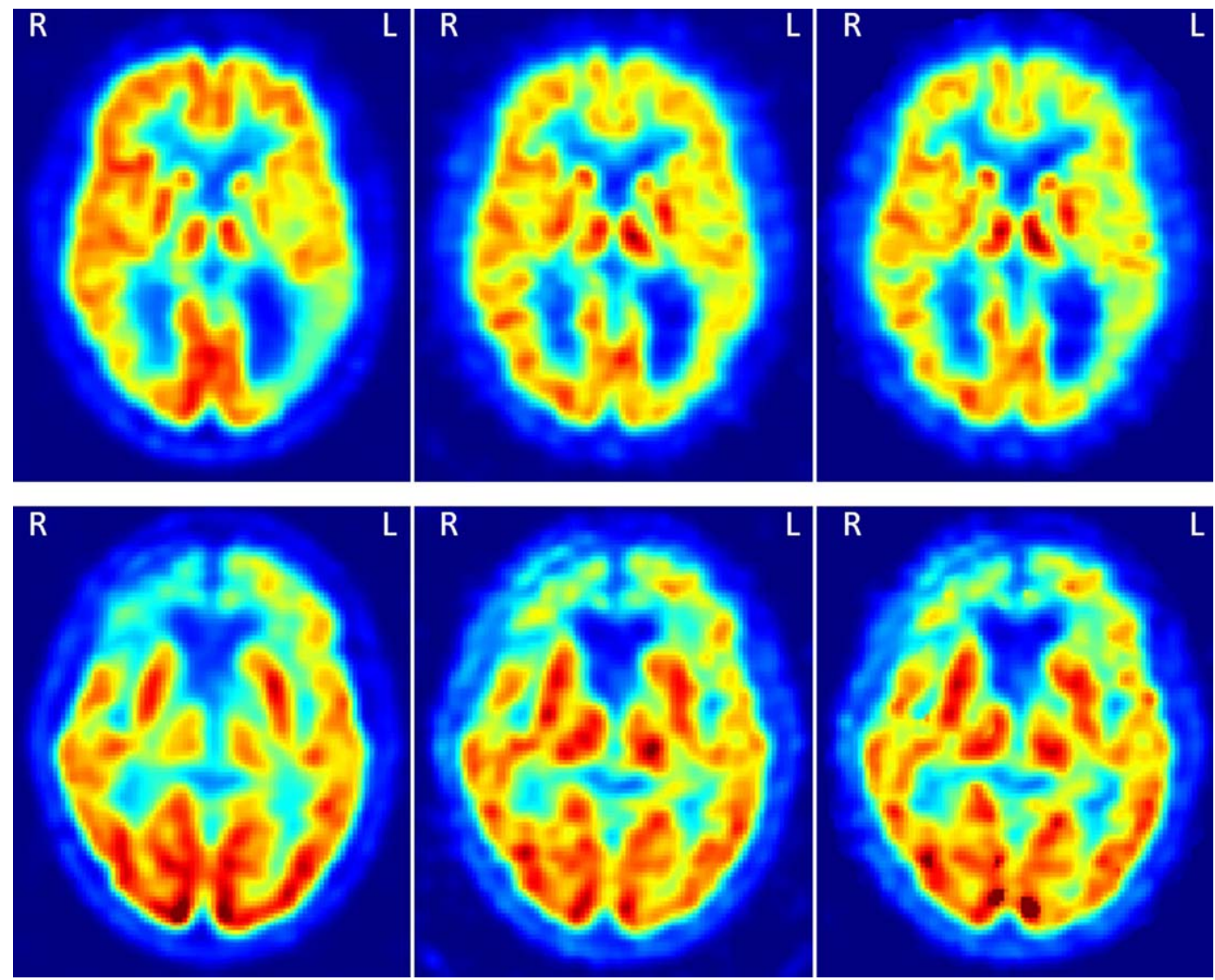

Fig. 3. Two examples of the FDG, pPiB(1-8min), and $\mathrm{R}_{1}(\mathrm{MRTM})$ images, respectively from the left to the right. The images on the top are from a patient with $\mathrm{AD}$, and on the bottom from a patient with FTD. In the top there is an asymmetric uptake in the parietal cortex and on the bottom an asymmetric uptake in the frontal cortex. These patterns can be seen in the three types of images. 
Table 2

Voxelwise regional Pearson correlation coefficient between the FDG and $\mathrm{R}_{1}$ or $\mathrm{pPiB}$ images

\begin{tabular}{lccc}
\hline Images & Median & Mean \pm SD & Range $(\min -\max )$ \\
\hline $\mathrm{R}_{1}$ (SRTM) & 0.826 & $0.809 \pm 0.093$ & $0.247-0.972$ \\
$\mathrm{R}_{1}$ (SRTM2) & 0.819 & $0.802 \pm 0.097$ & $0.194-0.977$ \\
$\mathrm{R}_{1}$ (MRTM) & 0.841 & $0.825 \pm 0.090$ & $0.345-0.981$ \\
$\mathrm{R}_{1}$ (MRTM2) & 0.838 & $0.820 \pm 0.094$ & $0.267-0.980$ \\
pPiB $(0-6$ min $)$ & 0.827 & $0.809 \pm 0.097$ & $0.276-0.984$ \\
pPiB $(1-8$ min $)$ & 0.838 & $0.817 \pm 0.097$ & $0.285-0.981$ \\
\hline
\end{tabular}

images can explain about $85 \%$ of the content of the FDG images. Figure 3 shows two examples of the FDG, $\mathrm{pPiB}(1-8 \mathrm{~min})$, and $\mathrm{R}_{1}$ (MRTM) images of two patients where it is easy to visually identify asymmetric uptake, which very likely indicates hypometabolism in region with lower FDG, $\mathrm{R}_{1}$ and $\mathrm{pPiB}$ values.

Repeated measures ANOVA with GreenhouseGeisser correction shows that there is a statistically significant difference $(F=23.359, p<0.001)$ among the correlation coefficients. Based on post hoc paired $t$-test with Bonferroni correction for multiple comparisons, it was observed that the correlation between the FDG and $\mathrm{R}_{1}(\mathrm{MRTM})$ images is significantly higher $(p<0.004)$ than the other correlations. Although statistically significant differences have been found among the mean computed correlations, the differences are low and with likely irrelevant biologically significance (lesser than 0.012).

There is not a statistically significant difference in the correlation between groups of patients, amyloid positive, amyloid doubtful or amyloid negative, per any type of images (Kruskal-Wallis test, $p \geq 0.180$ ), suggesting that their biological correlates remain the same across groups.

\section{Voxelwise regional correlation}

A summary of the results for all brain voxels Pearson correlation coefficients is shown in Table 2. Voxelwise correlations between FDG and $\mathrm{R}_{1}$ or $\mathrm{pPiB}$ were statistically significant in all brain voxels, except for the $\mathrm{R}_{1}$ (SRTM2) where it was nevertheless significant in more than $99.9 \%$ of the brain voxels. There is a statistically significant difference among the mean voxelwise whole-brain magnitude of correlations between the six types of images; however the difference of the mean is very low (maximum difference of the mean is 0.023). As can be seen in Table 2, the median of the Pearson correlation coefficient is higher than 0.81 , which means the correlation is strong or very strong in most of the brain voxels, irrespective of the particular model, suggesting that this proxy-based approach is relatively model independent.

Figure 4 shows the voxelwise correlation between the FDG images and the correspondent set of $\mathrm{R}_{1}$ (MRTM) images. As can be seen, the correlation is strong or very strong $(r \geq 0.7)$ in most of the brain. The regions where the correlation is not as robust are mainly in the transition between the grey and white matter. The distributions of the brain correlation between the FDG and the other $\mathrm{R}_{1}$ or $\mathrm{pPiB}$ images are similar.

\section{DISCUSSION}

In this work we performed a voxelwise analysis of the correlation between the FDG-PET images with the $\mathrm{R}_{1}$ or $\mathrm{pPiB}$ images computed from $\mathrm{PiB}$ PET dynamic acquisitions. Results show a very high $(r>0.9)$ mean within-subject Pearson correlation coefficient of the FDG images with the $\mathrm{pPiB}$ and $R_{1}$ images. A significantly higher correlation was found for the FDG- $\mathrm{R}_{1}(\mathrm{MRTM})$ against the correlation of the other pairs, however the difference had a very small effect size, and is therefore of likely irrelevant biological significance.

A previous study, Meyer et al. [3], also studied the correlation between $\mathrm{R}_{1}-\mathrm{PiB}$ and FDG images, but using only the SRTM2 kinetic model and a small dataset of 22 patients, while we tested four kinetic models for the computation of the $\mathrm{R}_{1}$ and used a dataset of 52 patients. Moreover, we further computed the correlation between the FDG and $\mathrm{pPiB}$ images using two time intervals and compared them with the correlation obtained between the $\mathrm{R}_{1}$ and FDG images. They found a slightly inferior within-subject correlation of approximately $r=0.79$ between the FDG and $\mathrm{R}_{1}$ generated by the SRTM2 [19], using a similar protocol acquisition. We think there are two main reasons that may explain our superior results. First, different datasets were used; second, the implementation of the algorithms, both the kinetic models and the image processing. As in Meyer et al. [3], we did not find a statistically significant difference in the correlation among groups of patients (amyloid negative versus amyloid borderline versus high amyloid deposition) for the $\mathrm{R}_{1}$ images. The same occurred for the pPiB images, suggesting that the use of these proxy measures is robust and independent of the used analysis method. 

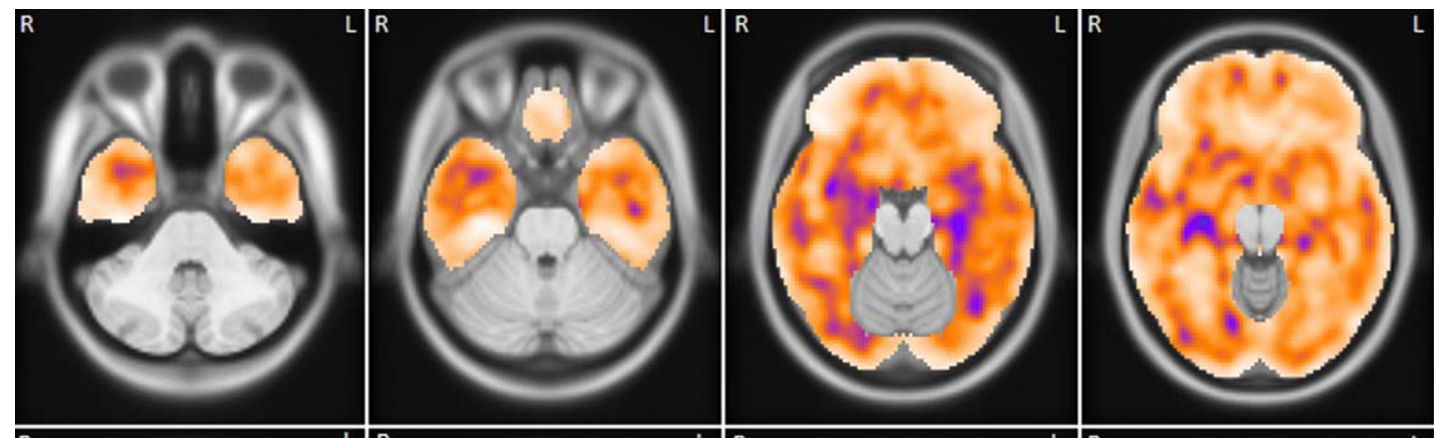

0.981
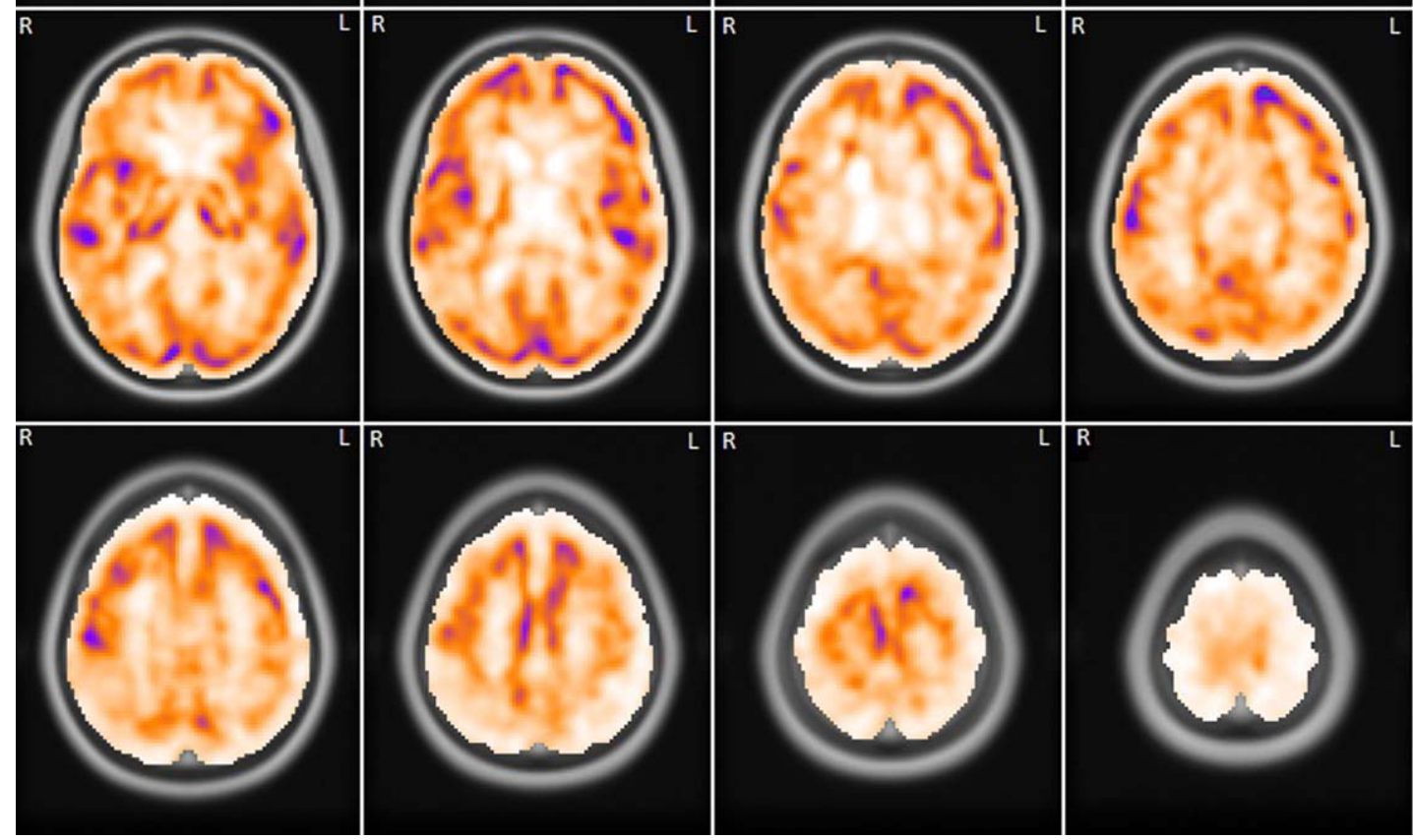

0.490

Fig. 4. Mean voxelwise correlation between the set of FDG images and the correspondent set of $\mathrm{R}_{1}(\mathrm{MRTM})$ images. The correlation image is overlapping the template MRI image.

Regarding the regional voxelwise correlation of the FDG images with the $\mathrm{pPiB}$ and $\mathrm{R}_{1}$ images, a high median voxelwise correlation was found for the six types of images $(r \geq 0.82)$. The regions with lesser correlation are mostly in the border between the grey and white matter. We think this can be partially explained by the image registration imperfections, since the uptake difference is higher from the grey matter to the white matter than within the grey matter or white matter.

We have opted to use the $\mathrm{R}_{1}$, pPiB and FDG images after intensity normalization since the standardized uptake value (SUV) of the FDG images are highly dependent on the several factors that are not related to the cerebral glucose metabolism, for instance, the blood glucose levels, insulin levels or anemia; and the $\mathrm{R}_{1}$ images depend on the free and non-specific binding in the cerebellar grey matter of each patient. Thus, after intensity normalization the variability of the uptake due to brain external factors is reduced, which is important for the computation of the voxelwise regional correlation. However, it is important to stress out that this normalization has no influence in the within-subject correlation, since the correlation is independent on scale factors.

In clinical practice, the $\mathrm{R}_{1}$ and $\mathrm{pPiB}$ images should not be normalized, neither spatially nor intensity. The spatial normalization may introduce distortions that difficult the clinical analysis and the SUV of the pPiB images may have clinical implications.

In a previous study, the SRTM2 and the MRTM2 methods were found as the best options to compute the $\mathrm{BP}_{\mathrm{ND}}$ for clinical studies [23]. These two methods have shown to be less affected by noise, 
producing $\mathrm{BP}_{\mathrm{ND}}$ images with better contrast than the images obtained from the other tested methods, and also because they provided the best accuracies in simulated studies. In our implementation, SRTM2 and MRTM2 originated $\mathrm{BP}_{\mathrm{ND}}$ images with less noise than the SRTM and MRTM methods, respectively; however, the $\mathrm{R}_{1}$ images had higher level of noise.

Intriguingly, SRTM and MRTM originated better quality $R_{1}$ images than their two steps version SRTM2 and MRTM2, respectively. This was not expected, since SRTM2 and MRTM2 have been used in previous studies and have originated high quality $\mathrm{R}_{1}$ and $\mathrm{BP}_{\mathrm{ND}}$ images [3, 6, 23]. In fact, in our implementation, the $\mathrm{BP}_{\mathrm{ND}}$ obtained using the SRTM2 and MRTM2 are of better quality than the $\mathrm{BP}_{\mathrm{ND}}$ obtained using the SRTM and MRTM, however the same did not happen for the $\mathrm{R}_{1}$ parametric images.

In terms of $\mathrm{pPiB}$ images, our results are as expected, since they confirm previous works where a significant correlation between the FDG and the PiB perfusion (pPiB) images was found $[4,5]$.

We have shown that there is high whole-brain within-subject correlation between $\mathrm{R}_{1}$ or $\mathrm{pPiB}$ and FDG measures (Fig. 2), however this is not enough to validate the $\mathrm{R}_{1}$ or $\mathrm{pPiB}$ images for a single-subject analysis compared with the FDG image [24], and thus these images cannot be used clinically to replace the FDG image before such evaluation. Other limitation of this study is that we cannot ascertain that the small differences found between the normalized $\mathrm{R}_{1}$ or $\mathrm{pPiB}$ images and the normalized FDG images do not hide some information related with neuronal injury. In any case, the work of Lin et al. [8] showed that the MMSE scores are significantly associated with the degree of perfusion impairment, which we believe is solid evidence for the usefulness of the $\mathrm{R}_{1}$ and $\mathrm{pPiB}$ images.

In conclusion, the results show that both $\mathrm{R}_{1}$ and pPiB images can explain about $85 \%$ of the content of the FDG images, and thus they may be of great importance to assess the synaptic dysfunction and neurodegeneration when the FDG images are not available. The higher correlation with the FDG images was found for the $\mathrm{R}_{1}(\mathrm{MRTM})$. However, the differences for the others $\mathrm{R}_{1}$ and $\mathrm{pPiB}$ images are rather small.

The $\mathrm{pPiB}$ images have originated results which are very close to the best $R_{1}$ images and are easier to compute, with shorter acquisition time. Thus they are probably the best choice to be computed routinely in the busy nuclear medicine centers. On the other hand, in centers where the $\mathrm{BP}_{\mathrm{ND}}$ images are computed for helping in the differential diagnosis, the $\mathrm{R}_{1}$ images may be the best choice, since they can be obtained simultaneously with the $\mathrm{BP}_{\mathrm{ND}}$ images.

\section{ACKNOWLEDGMENTS}

This work was supported by the following grants: Strategic project FCT-UID/NEU/04539/ 2013 - COMPETE, POCI-01-0145-FEDER-007440, BIGDATIMAGE, CENTRO-01-0145-FEDER000016, Centro 2020 FEDER, COMPETE, PAC MEDPERSYST, POCI-01- 0145-FEDER-016428.

Authors' disclosures available online (https:// www.j-alz.com/manuscript-disclosures/18-027 $4 \mathrm{r} 2)$.

\section{REFERENCES}

[1] Hardy J, Selkoe DJ (2002) The amyloid hypothesis of Alzheimer's disease: Progress and problems on the road to therapeutics. Science 297, 353-356.

[2] Paulson OB, Hasselbalch SG, Rostrup E, Knudsen GM, Pelligrino D (2010) Cerebral blood flow response to functional activation. J Cereb Blood Flow Metab 30, 2-14.

[3] Meyer PT, Hellwig S, Amtage F, Rottenburger C, Sahm U, Reuland P, Weber WA, Hüll M (2011) Dual-biomarker imaging of regional cerebral amyloid load and neuronal activity in dementia with PET and ${ }^{11} \mathrm{C}$-labeled Pittsburgh compound B. J Nucl Med 52, 393-400.

[4] Rostomian AH, Madison C, Rabinovici GD, Jagust WJ (2011) Early ${ }^{11}$ C-PIB frames and ${ }^{18}$ F-FDG PET measures are comparable: A study validated in a cohort of $\mathrm{AD}$ and FTLD patients. J Nucl Med 52, 173-179.

[5] Rodriguez-Vieitez E, Carter SF, Chiotis K, Saint-Aubert L, Leuzy A, Schöll M, Almkvist $O$, Wall A, Långström $\mathrm{B}$, Nordberg A (2016) Comparison of early-phase ${ }^{11} \mathrm{C}$ Deuterium-L-Deprenyl and ${ }^{11} \mathrm{C}-\mathrm{PiB}$ PET for assessing brain perfusion in Alzheimer's disease. J Nucl Med 57, 1071-1077.

[6] Chen YJ, Rosario BL, Mowrey W, Laymon CM, Lu X, Lopez OL, Klunk WE, Lopresti BJ, Mathis CA, Price JC (2015) Relative ${ }^{11} \mathrm{C}-\mathrm{PiB}$ delivery as a proxy of relative CBF: Quantitative evaluation using single-session ${ }^{15} \mathrm{O}$-water and ${ }^{11}$ C-PiB PET. J Nucl Med 56, 1199-1205.

[7] Daerr S, Brendel M, Zach C, Mille E, Schilling D, Zacherl MJ, Bürger K, Danek A, Pogarell O, Schildan A, Patt M, Barthel H, Sabri O, Bartenstein P, Rominger A (2017) Evaluation of early-phase $\left[{ }^{18} \mathrm{~F}\right]$-florbetaben PET acquisition in clinical routine cases. Neuroimage Clin 14, 77-86.

[8] Lin K-J, Hsiao I-T, Hsu J-L, Huang C-C, Huang K-L, Hsieh C-J, Wey S-P, Yen T-C (2016) Imaging characteristic of dual-phase ${ }^{18} \mathrm{~F}$-florbetapir (AV-45/Amyvid) PET for the concomitant detection of perfusion deficits and beta-amyloid deposition in Alzheimer's disease and mild cognitive impairment. Eur J Nucl Med Mol Imaging 43, 1304-1314.

[9] Forsberg A, Engler H, Blomquist G, Långström B, Nordberg A (2012) The use of PIB-PET as a dual pathological and 
functional biomarker in AD. Biochim Biophys Acta 1822, 380-385.

[10] Fu L, Liu L, Zhang J, Xu B, Fan Y, Tian J (2014) Comparison of dual-biomarker PIB-PET and dual-tracer PET in AD diagnosis. Eur Radiol 24, 2800-2809.

[11] McKhann GM, Knopman DS, Chertkow H, Hyman BT, Jack CR, Kawas CH, Klunk WE, Koroshetzl WJ, Manly JJ, Mayeux R, Mohs RC, Morris JC, Rossor MN, Scheltens P, Carrillo MC, Thies B, Weintraub S, Phelps $\mathrm{CH}$ (2011) The diagnosis of dementia due to Alzheimer's disease: Recommendations from the National Institute on Aging-Alzheimer's Association workgroups on diagnostic guidelines for Alzheimer's disease. Alzheimers Dement 7, 263-269.

[12] Albert MS, DeKosky ST, Dickson D, Dubois B, Feldman HH, Fox NC, Gamst A, Holtzman DM, Jagust WJ, Petersen RC, Snyder PJ, Carrillo MC, Thies B, Phelps CH (2011) The diagnosis of mild cognitive impairment due to Alzheimer's disease: Recommendations from the National Institute on Aging-Alzheimer's Association workgroups on diagnostic guidelines for Alzheimer's disease. Alzheimers Dement 7, 270-279.

[13] Gorno-Tempini ML, Hillis AE, Weintraub S, Kertesz A, Mendez M, Cappa SF, Ogar JM, Rohrer JD, Black S, Boeve BF, Manes F, Dronkers NF, Vandenberghe R, Rascovsky K, Patterson K, Miller BL, Knopman DS, Hodges JR, Mesulam MM, Grossman M (2011) Classification of primary progressive aphasia and its variants. Neurology $\mathbf{7 6}$, 1006-1014.

[14] Rascovsky K, Hodges JR, Knopman D, Mendez MF, Kramer JH, Neuhaus J, Swieten JCv, Seelaar H, Dopper EGP, Onyike CU, Hillis AE, Josephs KA, Boeve BF, Kertesz A, Seeley WW, Rankin KP, Johnson JK, Gorno-Tempini M-L, Rosen H, Prioleau-Latham CE, Lee A, Kipps CM, Lillo P, Piguet O, Rohrer JD, Rossor MN, Warren JD, Fox NC, Galasko D, Salmon DP, Black SE, Mesulam M, Weintraub S, Dickerson BC, Diehl-Schmid J, Pasquier F, Deramecourt V, Lebert F, Pijnenburg Y, Chow TW, Manes F, Grafman J, Cappa SF, Freedman M, Grossman M, Miller BL (2011) Sensitivity of revised diagnostic criteria for the behavioural variant of frontotemporal dementia. Brain 134, 2456-2477.
[15] Thal DR, Rüb U, Orantes M, Braak H (2002) Phases of $\mathrm{Ab}$-deposition in the human brain and its relevance for the development of AD. Neurology 58, 1791-1800.

[16] Klunk WE, Engler H, Nordberg A, Wang Y, Blomqvist G, Holt DP, Bergström M, Savitcheva I, Huang G-f, Estrada S, Ausén B, Debnath ML, Barletta J, Price JC, Sandell J, Lopresti BJ, Wall A, Koivisto P, Antoni G, Mathis CA, Långström B (2004) Imaging brain amyloid in Alzheimer's disease with Pittsburgh compound-B. Ann Neurol 55, 306319.

[17] Lammertsma AA, Hume SP (1996) Simplified reference tissue model for PET receptor studies. Neuroimage 4, 153158.

[18] Gunn RN, Lammertsma AA, Hume SP, Cunningham VJ (1997) Parametric imaging of ligand-receptor binding in PET using a simplified reference region model. Neuroimage 6, 279-287.

[19] Wu Y, Carson RE (2002) Noise reduction in the simplified reference tissue model for neuroreceptor functional imaging. J Cereb Blood Flow Metab 22, 1440-1452.

[20] Ichise M, Liow J-S, Lu J-Q, Takano A, Model K, Toyama H, Suhara T, Suzuki K, Innis RB, Carson RE (2003) Linearized reference tissue parametric imaging methods: Application to $\left[{ }^{11} \mathrm{C}\right] \mathrm{DASB}$ positron emission tomography studies of the serotonin transporter in human brain. J Cereb Blood Flow Metab 23, 1096-1112.

[21] Ibáñez L, Schroeder W, Ng L, Cates J, Consortium IS eds. (2005) The ITK Software Guide, Kitware, Inc., Clifton Park, NY.

[22] Gur RC, Ragland JD, Reivich M, Greenberg JH, Alavi A, Gur RE (2009) Regional differences in the coupling between resting cerebral blood flow and metabolism may indicate action preparedness as a default state. Cereb Cortex 19,375382.

[23] Yaqub M, Tolboom N, Boellaard R, Berckel BNMv, Tilburg EWv, Luurtsema G, Scheltens P, Lammertsma AA (2008) Simplified parametric methods for $\left[{ }^{11} \mathrm{C}\right] \mathrm{PIB}$ studies. $\mathrm{Neu}$ roimage $\mathbf{4 2}, 76-86$.

[24] Garibotto V, Morbelli S, Pagani M (2016) Dual-phase amyloid PET: Hitting two birds with one stone. Eur J Nucl Med Mol Imaging 43, 1300-1303. 